\title{
LEI ANTITERRORISMO NO BRASIL E A CENTRALIDADE DO MEDO NAS TRANSFORMAÇÕES DOS ESTADOS CONTEMPORÂNEOS
}

\section{Lara Sartorio Gonçalves ${ }^{1}$}

O medo é uma pressa que vem de todos os lados, uma pressa sem caminho...

João Guimarães Rosa

\begin{abstract}
Resumo: A partir do atentado do dia 11 de setembro de 2001, em Nova York, o terrorismo passou a constituir um tema central na sociedade. Desde então, medidas extremas de controle de territórios e populações são justificáveis, com implicações (geo)políticas e jurídicas a nível global. No período sequente ao atentado, medidas e legislações, como o conhecido Patriot Act, foram determinadas pelo governo estadunidense, de modo a tipificar o terrorismo e ampliar o poder e a prerrogativa dos governos em seu combate, autorizando recursos extralegais, vigilância e controle social. $\mathrm{O}$ que inicialmente parecia ser uma estratégia política reativa e pontual, tornou-se um projeto de Estado com alteração de paradigma que ambiciona expansão internacional por meio do compromisso com a "guerra ao terror". No Brasil, com as expressivas manifestações de Junho de 2013, desdobramentos jurídicos e políticos no sentido do "combate ao terrorismo" foram articulados pelos governos. Postura intrigante, dada a ausência de ataques terroristas no histórico do país. Neste artigo, refletimos sobre o caso brasileiro, a partir de método qualitativo e revisão bibliográfica, observando um padrão global de política do medo e deslocamentos da figura do inimigo externo para interno como mecanismos de autorização de políticas autoritárias.
\end{abstract}

Palavras-chave: Terrorismo; Lei Antiterrorismo; Estado; Medo; Movimentos Sociais.

\section{INTRODUÇÃO}

Apesar de não constituir um fenômeno novo, o terrorismo ganhou maior relevância na agenda política mundial a partir dos ataques de 11 de setembro de 2001. O investimento crescente no combate ao que se convencionou chamar de

1 Doutoranda e Mestre em Sociologia pelo Instituto de Estudos Sociais e Políticos (IESP/UERJ). Professora no Departamento de Ciências Sociais da Universidade Federal do Espírito Santo (UFES). Graduanda em Direito pela Universidade Federal do Estado do Rio de Janeiro (UNIRIO). Email: larasartorio@hotmail.com 
terrorismo pelas democracias liberais é central para compreender os contornos do Estado na contemporaneidade, ao menos no Ocidente. Há um arranjo paradoxal, e generalizante, que atrela a defesa de ideais democráticos à necessidade de políticas autoritárias e controle social. É certo que a hegemonização da "guerra ao terror" como palavra de ordem da democracia acentua esse paradoxo com efeitos determinantes para a política internacional hoje, bem como para a própria constituição dos Estados.

Marcadamente, a dinâmica processual que destaca o 11 de setembro trouxe à tona mudanças de relações e interações desveladoras do acúmulo de processos sócio-históricos. Correspondendo ao rigor de relacionar eventos locais com os processos estruturais (TILLY, 1996), é preciso apontar que um certo "estado de emergência permanente" (AGAMBEN, 2004) vem sendo justificado e hoje ocupa o lugar de paradigma dominante de governo. Aquilo que antes figurava nos termos da exceção ${ }^{2}$, ou seja, zona de indefinição entre o direito e a política, baseado no "estado da necessidade" de casos extremos que demandam a suspensão da ordem jurídica, passa a caracterizar o Estado Moderno em suas práticas regulares.

A "guerra ao terror", mote da rearticulação internacional, não se trata de evento cristalizado em período determinado. Como sugere Tilly, a guerra não é um evento bélico, que acontece em si mesma, mas sim um processo. E enquanto tal, envolve aspectos de preparação, mobilização e burocratização. $\mathrm{O}$ chamado internacional proposto pelo governo dos Estados Unidos explora esse aspecto de processualidade da guerra, enfatizando as três dimensões na medida em que altera a interatividade global. Com efeito, a "guerra constitutiva do Estado" (TILLY, 1985) desorganizou os arranjos internacionais, expondo e acentuando as relações contraditórias com o território (tanto de centralizações do poder quanto de acumulações de ação coletiva) e com a aderência a nível subjetivo da população.

Por um lado, temos que o Estado se fortalece e é justificado pela prerrogativa da necessidade: real ou não, sustentadora de um argumento de alto grau de aderência pública e com respaldo extrajurídico/político ${ }^{3}$ da exceção. E, por outro, temos uma sociedade orientada pela "menoridade política", que

2 Cabe destacar uma discussão lateral, nos termos do presente artigo, mas central para pensar a democracia moderna, que a lógica de "exceção" como conclusiva para refletir as práticas autoritárias, e mesmo antidemocráticas, da atualidade, nos confrontam com outras questões elementares sobre a origem da noção de "democracia". Para tanto, é necessário recuperar como a representação/participação/controle da população foram formuladas de modo paradoxal na teoria clássica. Nesse sentido, a ideia de "exceção" pode acabar por eximir a própria ideia de "democracia" como, em si mesma, limitada e contraditoriamente edificada.

3 Como bem aponta Agamben, em Estado de Exceção (EE), o debate sobre o EE é bastante pautado por esse espectro de definição de uma regulação por fora do ordenamento jurídico. A confusão que se estabelece entre direito e política a partir desse mecanismo legal que prevê o ilegal resulta em questionamentos quanto ao locus do EE. Em geral, o dilema de circunscrição do EE consiste em considerá-lo "extrajurídico" ou "político", propriamente. 
delega poder pela relação em que a obediência é ofertada em troca de proteção. Assim, com frequência se confirma a tendência em políticas autoritárias de controle social são não apenas autorizadas, como muitas vezes também demandadas. É o que demonstra, por exemplo, a aprovação da população quanto à Intervenção Federal ${ }^{4}$, em 2018, no Rio de Janeiro ${ }^{5}$. O exemplo da Intervenção Federal é ilustrativo, tendo em vista o lugar de excepcionalidade jurídica que ocupa, em que dinâmicas do próprio federalismo brasileiro, cláusula pétrea de nossa constituição, é ferido pela justificativa da "necessidade". Está no mesmo patamar das excepcionalidades do Estado de Sítio e Estado de Defesa.

O que se observa, nesse sentido, é que os recursos ao autoritarismo não apenas estão previstos pela regularidade do sistema, como, por fim, não necessariamente violam os princípios democráticos liberais, dado seu alto grau de abstração e flexibilidade aos recursos de controle social, em especial no que tange à segurança pública. É certo que a prerrogativa autoritária do Estado está ancorada na noção originária do Estado como gestor da violência e do medo, na medida em que o "momento constitutivo" de todos os poderes terrenos é a "violência, a repressão e a falsidade", assim como o "tremor e o medo dos subjugados", tal como aponta Mikhail Bakhtin.

Dessa relação, segue-se que a política passa a orientar e ser orientada pelo medo, inflexionada pela demanda por segurança. De modo que o que atribui sentido ao conjunto problema-solução "livrar os homens do medo" (problema) através da segurança e da ordem (solução), é de que o medo se relaciona com a indeterminação, o imprevisível e o invisível. Isto é, o governo serve, em sua lógica, não para interromper ou dar fim àquilo que ameaça, mas para mostrar por onde andar, qual caminho seguir. O medo impulsiona um cálculo em que é contratada a submissão como forma de salvar a vida, ou seja, aceita-se uma maior vigilância a partir da compreensão de que esta está relegada à contenção do "outro" e não de si.

$\mathrm{Na}$ interação do poder com o território, todo um povo foi localizado como "eixo do mal" e ao redor do mundo foi constituída a imagem estigmatizada dos "portadores da ameaça". Variações dessa dinâmica podem ser verificadas a

4 Como pode ser verificado pela pesquisa da Datafolha. Disponível em: $<$ https://wwwl.folha.uol.com.br/cotidiano/2018/09/72-dos-moradores-do-estado-do-rio-queremprorrogar- intervencao-federal.shtml> Acessado em: 04 de fev. de 2019.

O paradoxo dessa aprovação é o legado de violência da Intervenção. O relatório final do "Observatório da Intervenção" demonstra que o investimento bilionário ( $\mathrm{R} \$ 1,2$ bilhão de reais) na intervenção não produziu alteração relevante nas questões de segurança pública do Rio de Janeiro. Ao contrário, acentuou as fórmulas de segurança pública que já tradicionalmente não traziam resultados. A finalizou com 1.375 mortos por intervenção de agentes do Estado de fevereiro a dezembro de 2018, 33,6\% mais que o mesmo período em 2017. Outros tantos legados que provam malogro da Intervenção podem ser encontrados no relatório do próprio Observatório. Disponível em: <https://drive.google.com/file/d/1UPulZi6XpsK8DQo6c5oVmwUFUhypkOpA/view> Acessado em: 29 de nov. de 2019. 
partir de duas inflexões, que podemos caracterizar desde a i) relação externa: o inimigo-terrorista de países do "eixo do mal'. Essa categoria nos auxilia pensar a imigração e seus problemas; a xenofobia; o racismo; a demarcação de toda uma região do mundo como "território hostil"; e ii) relação interna: o inimigocriminoso doméstico, aquele que ocupa os territórios periféricos em seus próprios países, com um recorte de classe (pobre) e raça (negro) bem acentuado.

Meio a esse contexto de potencial violência encarnada na figura do Outro, o imaginário do medo e uma política de temporalidade antecipatória, marcada pela "prevenção do mal e da hostilidade", somam-se a última crise migratória e o surgimento - e fortalecimento - do Estado Islâmico ${ }^{6}$.

A estrutura lógica sobre a qual se assenta as discussões sobre terrorismo internacional nos permite compreender os contextos de surgimento do Estado Islâmico, dentre outros grupos extremistas associados ao oriente médio, como um dos principais fatores para a atual crise migratória. Foram atribuídos a esses grupos os atentados em Paris, de 13 de novembro de 2015, que vitimou mais de uma centena de pessoas, e o ataque ao jornal Charlie Hebdo no início desse mesmo ano, por exemplo.

A França, que enfrenta os efeitos da crise migratória, é um bom ponto de partida para a compreensão desse momento, por sua também recém aprovada Lei Antiterrorismo. Assim como no Brasil, conforme verificaremos mais detalhadamente à frente, organizações políticas, movimentos sociais e entidades de defesa dos direitos humanos resistiram à legislação na França. Um dos atos de oposição de maior destaque naquele país foi a renúncia da Ministra da Justiça Christiane Taubira em razão da aprovação da lei (CHARLEAUX, 2016).

Esse efeito jurídico da pressão de países poderosos, como Estados Unidos e Israel, tem orientado a própria configuração de Estado, especialmente após o "11 de setembro". Um Estado punitivo, vigilante, com centralidade nas ações policiais investigativas e repressoras, vem sendo formado nos países que cedem aos tensionamentos impostos pelos Estados Unidos quanto à participação na "guerra ao terror". No Brasil, medidas jurídicas foram encabeçadas pelos governos, a partir de 2013: projeto de lei municipal do Rio de Janeiro ( $\mathrm{n}^{\circ}$ 2405/2013) e a lei municipal de São Paulo (Lei $n^{\circ}$ 15556/2014) relativas à proibição do uso de máscaras nas manifestações e, em sequência, a Lei Antiterrorismo (PLC 101/2015). Esta última, sancionada pela então presidente Dilma Rousseff. 


\section{DEFINIÇÃO E DILEMAS DO TERMO "TERRORISMO"}

O terrorismo, menos como conceito e mais como espectro que ronda as estratégias políticas, é não apenas tema de relevância central, mas um enquadramento das relações internacionais. Apresentá-lo fora da esteira dos conceitos, neste artigo, tem a ver com destacar enfaticamente, desde já, a questão que subjaz o termo. As palavras terror, terrorismo, terroristas, são reiteradamente abordadas como "conceitos inseparáveis, entidades coerentes, atores eficazes, e inimigos a serem erradicados" (TILLY, 2004). Agentes de Estado, em especial dos Estados Unidos e Israel, como muitos de seus discursos demonstram $^{7}$, mobilizam os termos como noção unitária e coesa, apontando para uma reificação equivocada e, ainda assim, poderosa. É certo que esse recurso exerce uma influência significativa na política mundial.

O termo terrorismo entrou no vocabulário ocidental a partir da Revolução Francesa, no chamado período do terror (WARDLAW, 1982), marcado pelas ações dos revolucionários contra seus inimigos domésticos nos anos de 1793 e 1794. Se referia, nesse contexto, à repressão governamental, diretamente relacionada às execuções que marcaram o período (17 mil execuções legais ocorreram sob o Reinado do Terror, e aproximadamente 23 mil mais ocorreram de maneira ilegal).

Desde então, a palavra terror expandiu em escopo. Apesar de alguns especialistas ainda usarem para tratar de ações governamentais, o termo é frequentemente mobilizado para designar ataques clandestinos contra alvos governamentais. Outras vezes é também usado para caracterizar limpezas étnicas e genocídios (TILLY, 2004). Terrorismo então vai sendo apropriado para designar uma ampla gama de crueldades humanas e, com isso, cada vez menos rigoroso em definição. A aplicação do termo, entretanto, é, invariavelmente, uma escolha política. E como se prova com recorrência nos últimos vinte anos: "a despeito da falta de clareza e da nítida discordância entre Estados UnidosIsrael e o mundo, as definições oficiais americanas de terrorismo são bastante adequadas às finalidades momentâneas" (CHOMSKY, 2004: 193).

Charles Tilly (2004) opta por atribuir sentido estratégico ao termo, com intenção de torná-lo replicável a distintos contextos. $\mathrm{O}$ autor define a estratégia do terror como aplicação assimétrica de ameaças e violência contra alvos vulneráveis por meio de uma "ampla variedade de circunstâncias políticas, na companhia de tipos muito diferentes de luta política" (TILLY, 2004: 10). Desse modo, Tilly desloca o terrorismo de sua noção mais recorrente como fenômeno 
de causa singular dotado de coerência. Em alguma medida, resolve a dificuldade das definições do ato terrorista que requerem informação no campo das motivações e intenções, critérios muito difíceis de verificar, pois raramente vem à tona em violências coletivas.

Feita essa observação conceitual, podemos pensar como a discussão do terror vem cumprindo um papel fundamental na constituição de imaginários coletivos sob as ações estatais no ocidente. Wardlaw (1982) aponta que a singularidade das ações políticas de terror é seu efeito psicológico, que são "ansiedade extrema ou medo". Passados tantos anos, atentados e repercussões da análise feita por Wardlaw, é responsável que atualizemos sua tese para os efeitos não somente dos atos de terror, mas especialmente o uso de seus efeitos psicológicos, tão característicos.

Podemos dizer que a sociedade contemporânea é marcada fundamentalmente por esse uso do medo enquanto afeto político (SARTORIO, 2018). Com a violência disseminada e seus meios de divulgação, houve um investimento da produção simbólica do medo como afeto justificador do controle e disciplinamento social. Safatle registra que, desde Aristóteles, "medo implica preparo e reação diante de um perigo real, iminente ou imaginado" (SAFATLE, 2016:50). O medo, enquanto afeto político, tende a "construir a imagem da sociedade como um corpo tendencialmente paranoico, preso à lógica securitária do que deve se imunizar contra toda violência que coloca em risco o princípio unitário da vida social". Imunidade que precisa da perpetuação funcional de um "estado potencial de insegurança absoluta vinda não apenas do risco exterior, mas da violência imanente da relação entre indivíduos" (SAFATLE, 2016: 20).

A barbárie atual, marcada pela difusão de uma violência impossível de ser contida, se instala em relação retroalimentada com a gestação do medo e sua gestão, em segurança. Estamos falando de uma sociedade da insegurança total, característica que marca as sociedades neoliberais contemporâneas.

A ideia de "fábrica do medo" implica pensar em relações de produção do medo. É sabido que o Estado controla a obediência dos cidadãos a partir da promessa de protegê-los das ameaças à existência. Assim, há uma espécie de ubiquidade da segurança e dos medos. Aqueles de que provém a segurança, e os que inspiram medo. É assim que, com tranquilidade, os discursos produzidos pelos Estados quanto ao "terrorismo", "vandalismo" e "delinquência" são facilmente alocados em estereótipos de minorias e os [os Estados] eximem instantaneamente de serem classificados enquanto tais (SARTORIO, 2018). 


\section{11 DE SETEMBRO E A “GUERRA CONTRA O TERROR"}

Estar "em guerra" inverte o próprio lugar político do Estado. Conforme escreve Hobbes, recordado por Chamayou: "todo homem é impelido pela natureza, na medida em que isso lhe é possível, a proteger na Guerra a autoridade pela qual é protegido em tempos de paz". Aqui, a relação de proteção é invertida: enquanto na paz, o soberano me protege, na guerra, eu protejo o soberano (CHAMAYOU, 2015: 196). Note que, nessa estrutura de Estado, mesmo as lógicas contratualistas se deparam com um paradoxo. Exige-se do súdito uma obediência que tem por fim a proteção e garantia da própria soberania, do Estado.

Nesse sentido, após o atentado de 11 de setembro de 2001, o debate em torno do terrorismo e da segurança vem sendo acentuadamente explorado pelos governos dos Estados Unidos. A chamada "guerra contra o terror" promoveu atrocidades que constituíram novos marcadores na política internacional, no sentido de ingerência, intervenções e mesmo concepções de guerra. Sob o seu impacto, o Congresso estadunidense aprovou, por uma esmagadora maioria (98 votos a 1 no Senado, e 357 a 66 na Câmara dos Deputados), em outubro de 2001, o U. S Patriot Act (Ato Patriótico Americano) que ampliou os poderes do FBI, da polícia federal norte-americana, a competência dos serviços de informação sobre a vigilância de pessoas e os poderes de outras agências de manutenção da ordem.

A lei foi renovada pelo Congresso em 2006, autorizando, segundo Débora Pastana (2011), que o governo norteamericano pudesse

[...] conduzir operações em sigilo, reprimir manifestações, colocar pessoas sob vigilância (mesmo sem qualquer prova que justifique a suspeita) ou recolher, com o objetivo de levar adiante uma investigação, informações confidenciais sobre a vida privada de cidadãos norte-americanos, bem como de estrangeiros residentes nos Estados Unidos (PASTANA, 2011: 93)

Uma série de arbitrariedades do governo dos Estados Unidos, em âmbito internacional, foram perpetradas. As invasões dos Estados Unidos no Iraque e Afeganistão são exemplos de reação mais imediata ao atentado "11 de setembro". Como sugere Chomsky, a única conexão da invasão ao Iraque com o terrorismo foi o verificado aumento exponencial do terrorismo e a consolidação de uma política de Estado pautada pela disseminação do medo e do terror. Nenhuma das justificativas utilizadas pelos EUA para atacar o país foram confirmadas, inclusive "o suposto vínculo de Saddam Hussein e Osama Bin Laden, na verdade seu inimigo figadal, baseava-se em provas sem credibilidade que já haviam sido descartadas por observadores competentes" (CHOMSKY, 
2004: 25).

Dentre as ações perpetradas pelos Estados Unidos, nesse período, há também a instalação, em território cubano, da base de Guantánamo, apara a qual são enviadas pessoas acusadas de práticas de terrorismo. Os encarcerados da prisão de Guantánamo possuem seus direitos e a própria condição de humanidade suspensos (CHOMSKY, 2008). E para que o indivíduo seja acusado das práticas que o conduzem ao encarceramento, Chomsky nos aponta que "um combatente inimigo pode ser qualquer um que os Estados Unidos resolvam atacar, sem provas convincentes, conforme admite Washington" (CHOMSKY, 2004: 33). Desse modo, o que se vislumbra é que na base de Guantánamo os presos não são considerados réus de um processo criminal e sequer considerados prisioneiros de guerra, o que lhes garantiria os direitos previstos na Convenção de Genebra.

Como respaldo, os EUA criam uma nova categoria jurídica, "inimigos combatentes ilegais", parte da "Doutrina Bush", o que autoriza que uma pessoa seja presa sem a necessidade de respeito a habeas corpus, podendo ser sujeitos à tortura. Desse modo, a política contra o terror promovida pelo governo estadunidense pode ser traduzida como ação de estado de exceção, na medida em que a sujeição dos prisioneiros de Guantánamo a uma detenção indeterminada demonstra um extrapolação das prerrogativas do poder soberano (AGAMBEN, 2004), por transpor as garantias ratificadas junto à Organização das Nações Unidas, tratados e convenções internacionais. A indeterminação e ambivalência das fórmulas legislativas é deliberadamente instrumentalizada em tema de terrorismo, justamente por permitir àquele [nesse caso, o Estado] que o manuseia interpelar o conteúdo que preferir.

Responsável por Guantánamo, o general Geoffrey Miller definiu o princípio geral que rege a prisão: "eles são como cães, e se você os deixa acreditar em algum momento que são mais do que cães, então você perdeu controle sobre eles"8. Não se distancia muito desta alarmante declaração o outro exemplo atroz, utilizado como símbolo de intimidação global pelos Estados Unidos: a prisão de Abu Ghraib. Edificada no Iraque, esse foi um verdadeiro campo de concentração de encarcerados frequentemente torturados.

A forma do Estado, nesse sentido, é recriada e concebida como agente de segurança da sociedade civil. Entretanto, a integridade da sociedade passa, nessa lógica, pela garantia e proteção da própria forma Estado. A obediência se refere ao Estado em um lugar não mais de produto da organização e ação das vidas em sociedade. Ao contrário, as vidas passam a ser produtos dele, cedidas de modo condicional. Que corpos políticos são esses, assumidos como vidas que existem por consentimento/autorização do Estado? Nas reflexões de Chamayou: "todo poder protetor precisa da vulnerabilidade de seus protegidos

8 Citação extraída do texto de Mário Maestri. Disponível em: <https://www.correiocidadania.com.br/ antigo/ed490/int1.htm> Acessado em: 29 de nov. de 2019. 
- admitindo a possibilidade, na falta dela, como todos os chantagistas bem sabem, de ele próprio mantê-la ativamente" (CHAMAYOU, 2015: 201).

O que se evidencia, pela mobilização ativa do discurso do terrorismo, em especial em casos mais estridentemente paradoxais, como é o caso do Brasil, é que a produção e reprodução de condições de vulnerabilidade são afetivamente - e efetivamente- ativadas pelo medo. Medo de um Estado desprotegido e, logo, da sociedade - por ele criada - destruída (terror). E medo do Estado ativo, exercendo sua plena dominação e controle.

\section{BRASIL}

O segundo semestre de 2013, no Brasil, marcou a história do país pela quantidade expressiva de manifestantes nas ruas e frequência de mobilizações com alto grau de capilaridade em todo o território nacional. Junho de 2013 é considerado uma das maiores mobilizações sociais da democracia brasileira, que teve um caráter diverso e ainda hoje divide os analistas quando a seu diagnóstico e prognóstico. A inflexão que o fenômeno representa se desdobra no Estado como busca de se fortalecer no sentido da punição, controle e contenção repressora dessas mobilizações. Assim, o contexto de junho de 2013 foi fator de grande relevância para a retomada do debate sobre terrorismo no país.

Antes de tudo, é preciso frisar que a discussão quanto à criação de leis que tipifiquem o terrorismo não é nova e já estava posta como pressão aos Estados do Ocidente desde que a doutrina Bush definiu diretrizes da "guerra ao terror" ${ }^{\text {. }}$ No Brasil, diversos projetos de lei que buscaram a tipificação do crime foram elaborados, mas, até a efervescência política ocasionada por Junho de 2013, nenhum deles havia avançado significativamente rumo à efetiva aprovação.

À guisa de retrospectiva recente, o BOPE (Batalhão de Operações Policiais Especiais), força de operações especiais da Polícia Militar do Estado do Rio de Janeiro (PMERJ), empenhou política preocupada com a preparação e a capacitação de seus agentes, tendo em vista a aproximação dos megaeventos (Copa do Mundo FIFA de 2014 e Jogos Olímpicos de Verão 2016) na capital carioca. Lançou um programa ${ }^{10}$ em 2010 que se dedicava a estudar grupos terroristas e aprimorar o condicionamento físico dos agentes. $\mathrm{O}$ curso foi organizado de modo a realizar treinamento local e intercâmbio dos policiais

9 Conforme justificativa apresentada, no caso brasileiro, a criação da lei está vinculada à Convenção Interamericana contra o Terrorismo (CICTE) de 2002, que em seu artigo $4^{\circ}$, estabelece que os Estados-Membros da Organização dos Estados Americanos (OEA) devem estabelecer parâmetros legais para combater o terrorismo.

10 O que se configurou como treinamento parte da 18a edição do COEsp (Curso de Operações Especiais) do BOPE. 
com Israel, para treinamento em técnicas contra o terrorismo ${ }^{11}$. O governo brasileiro, à época, divulgou em seu site oficial a convocatória desses intercâmbios ${ }^{12}$.

O retorno do debate no contexto de Junho de 2013, por meio do primeiro projeto de lei antiterrorismo, torna explícito o caráter e o alvo do projeto, tendo em vista sua apresentação no calor das manifestações, o PLS 499/2013. A apresentação do projeto gerou polêmica e contestação, mas a expectativa de sua aprovação se intensificou especialmente após o episódio, na ocasião de uma manifestação no centro do Rio de Janeiro, no qual o cinegrafista Santiago Andrade veio a falecer após ser atingido por um rojão na cabeça, sendo dois jovens manifestantes os acusados de terem dado causa à tragédia.

Outros elementos corroboraram a importância e o efeito conjunturais de 2013: a numerosa quantidade de projetos legislativos produzidos neste momento que não se reduzem à temática direta de terrorismo, mas que evidenciam a preocupação de conter e reprimir as mobilizações no país. Os discursos públicos dos parlamentares responsáveis pela aprovação da lei justificavam-na por duas vias: quanto à adequação das exigências internacionais e corporativas frente os megaeventos. E quanto à necessidade de suprir a lacuna do ordenamento jurídico, derivada de normas da Constituição, que prevê "em seu art. $4^{\circ}$, VIII, o compromisso do país com o repúdio ao terrorismo e, em seu art. $5^{\circ}$, XLIII, que o terrorismo constará no rol dos crimes inafiançáveis e insuscetíveis de graça ou anistia" (CONCEIÇÃO, ZANOTTELI, 2016).

Dentre as novas criminalizações previstas por projetos de lei no mesmo contexto, temos: crime de vandalismo, a infração do anonimato e uso de máscaras em manifestações, aumento de pena para condutas já previstas como crimes que foram, de alguma forma, conectados a práticas visualizadas nas manifestações contrárias aos grandes eventos, que é o caso do crime de dano.

Nas justificativas desses projetos ${ }^{13}$ é notável o elemento comum de menção direta à necessidade do controle da atuação de militâncias, que ao supostamente

fugirem de um certo padrão estratégico e tático esperado em dissidências democráticas e caírem em um alegado radicalismo, poderiam converter-se em um perigo interno e deveriam, portanto, deixar de serem consideradas como atores legítimos nas disputas

11 Apesar da dificuldades de informações assertivas e detalhadas sobre a temática, essas são de acesso público. Disponíveis em: <http://odia.ig.com.br/portal/rio/terrorismo-deixa-o-bope-em-alerta1.261085> <http://odia.ig.com.br/portal/rio/curso-do-bope-fica-ainda-mais-duro-para-combaterterrorismo-1.227282> $<$ https://pt.wikipedia.org/wiki/Batalh\%C3\%A3o_de_Opera \%C3\%A7\%C3\%B5es_Policiais_Especiais_(P MERJ)> Acessados em: 30 de nov. de 2019.

12 Disponível em: <http://www.brasil.gov.br/defesa-e- seguranca/2011/03/policiais-brasileiros-podemse-candidatar-a-curso-em-israel $>$ Acessado em: 30 de nov. de 2019.

13 A ONG Artigo 19 (2014) publicou um levantamento que aponta que 21 projetos de lei sobre protestos foram criados entre 2011 e 2013 (p. 36). Disponível em: <http://protestos.artigo19.org/Protestos_no_Brasil_2013.pdf> Acessado em: 30 de nov. de 2019. 
democráticas. As criminalizações se apresentariam, assim, como importantes estratégias de reorganização das arenas de disputa política para o afastamento - ou eliminação - dos ilegítimos (CONCEIÇÃO, ZANOTTELI, 2016: 280).

Somente no período das manifestações de 2013 e nos anos seguintes, ainda como desdobramentos desse marco, outros projetos além do PLS 499/2013 foram criados buscando a tipificação do terrorismo. Podemos citar como exemplos: o PL 5571/2013, do Deputado Alexandre Leite (DEM-SP) e o PL 4672/2012, do Deputado Onyx Lorenzoni (DEM-RS). Outros projetos mais recentes, como o PL 1594/2015, do Deputado Lincoln Portela (PR-MG), e o PL 2294/2015, do Deputado André Figueiredo (PDT-CE), ambos apensados ao PL 2462/1991. Há, também, o PL 2583/2015, proposto por Ronaldo Carletto (PPBA), apensado ao PL 1378/2015, proposto pelo Deputado Arthur Virgílio Bisneto (PSDB-AM), que, por sua vez, também está apensado ao PL 2462/1991. Outra proposta de tipificação foi por meio do projeto do Deputado Edson Pimenta (PSD-BA), o PL 3714/2012, hoje apensado ao PL 7765/2010, o qual, por sua vez, segue apensado ao PL 149/2003.

A lei antiterrorismo foi recebida, em junho de 2015, na Câmara dos Deputados em regime de urgência. Em agosto de 2015, após algumas modificações, o projeto foi aprovado na Câmara, ou seja, com rapidez relativa surpreendente. Nos termos dos textos propostos tanto pela própria Câmara (art. $2^{\circ}, \$ 2^{\circ}$ ) quanto pelo poder executivo (art. $1^{\circ}, \S 3^{\circ}$ ), estariam excluídos do tipo penal do terrorismo as manifestações políticas e os movimentos sociais ou sindicais. No projeto enviado pelo Poder Executivo, porém, foi prevista a possibilidade de o terrorismo ser compreendido também como atos cometidos em razões de ideologia ou política - questão extremamente problemática trecho este retirado posteriormente pela Câmara após a tramitação na Casa.

Ao ser recebido no Senado Federal para apreciação, foi substituído por um projeto ainda mais rigoroso, de autoria do Senador Aloysio Nunes Ferreira (PSDB-SP). O texto final foi sancionado pela presidenta Dilma Rouseff em 16 de março de 2016, nove meses após o anteprojeto ser oferecido em regime de urgência, rapidez que rememora a promulgação do USA Patriot Act. Em fevereiro de 2019, a lei antiterrorismo foi novamente discutida e aprovada no âmbito da Câmara, porém com a retirada da parte mais diretamente relacionada a protestos e movimentos sociais.

No momento seguinte à aprovação da legislação, é anunciado o chamado "Pacote do Moro", um pacote anticrime proposto pelo então futuro Ministro da Justiça e da Segurança Pública no governo Bolsonaro, Sérgio Moro. Nesse pacote, 14 leis são alteradas, propondo uma fórmula já desgastada de política criminal, que consiste em mais penas, mais tipos penais, mais prisões e menos garantias processuais. A proposta vem com acentuado alargamento das prerrogativas policiais, ampliação da legítima defesa para agentes de segurança 
pública, mudança do tipo penal de desacato, redefinição de organizações criminosas de modo a afetar, principalmente, como já demonstrado nas experiências brasileiras e outros países, os movimentos sociais.

A lei, logo depois de ser sancionada, já foi recorrida no contexto das Olimpíadas no Brasil, pelo então presidente interino Michel Temer. Como reação ao acontecimento na França, Nice, atribuído a terroristas, Temer publicou um decreto que aumentava em $150 \%$ o valor da diária de servidores públicos, entre eles agentes da Força Nacional, e autorizou a contratação de inativos da polícia militar, como forma de estimular a ostensividade militar no evento.

No mesmo ano, quatro militantes do MST (Movimento dos Trabalhadores Rurais Sem Terra) foram condenados e enquadrados como pertencentes a organização criminosa, o absurdo teve amparo nas reformas legislativas da lei antiterror que redefine o conceito de organizações criminosas ${ }^{14}$. A situação é agravada pelas declarações recentes proferidas pelo atual presidente Bolsonaro, que esbravejou, ao comentar o caso, que "toda ação do MST e do MTST devem ser tipificadas como terrorismo. A propriedade privada é sagrada ${ }^{15 "}$.

Os alvos da tipificação reforçam os argumentos dos movimentos sociais, sublinhados pela declaração do Ministro da Defesa de que "os órgãos de inteligência já haviam detectado quinhentos mil suspeitos de terem alguma relação com o terrorismo" (FANTTI, 2016). É certo que um número tão expressivo não pode significar outra coisa senão que o conceito de terrorismo adotado é extremamente vago ou com propósitos persecutórios de qualquer um que se apresente como potencial opositor político.

\section{A TITULO DE CONCLUSÃO: POLITICA DO MEDO}

Ao conceber o Estado e seus mecanismos como responsáveis pela difusão da cultura do medo e de suas fronteiras, a consequência mais imediata é a consolidação de um viés punitivo e justificador de demandas por segurança. Sob essa perspectiva, o modo de produção capitalista foi especialmente eficaz em um processo de despolitização do medo, transformando-o em mecanismo indutor de políticas autoritárias de controle social.

Jasmin (2013) recupera Tocqueville para apontar consequências políticas

14 Foram reportadas, nesse período, outras prisões enquadradas na Lei Antiterrorismo. Disponível em: <http://gl.globo.com/jornal-nacional/noticia/2016/07/pf-prende-10-suspeitos-em-operacao-contrao-terrorismo-no-brasil.html> Acessado em: 29 de nov. de 2019.

15 Disponível em: <https://www.em.com.br/app/noticia/politica/2018/10/29/interna_politica,1001378/ nao-tem-conversa-com-o-mst-diz-jair-bolsonaro.shtml> Acessado em: 29 de nov. de 2019. 
do medo para a sociedade moderna. A revolução democrática constituiria uma sociedade em que a "mediocridade da cultura das classes médias" seria firmada pelo medo da instabilidade social que os faz viver em "busca incessante da riqueza e do bem-estar material". Uma das consequências seria uma sociedade de indiferença cívica, inserida numa lógica de eterna "menoridade política", ou seja, um desejo por ordem pública e o horror radical às turbulências sociais (JASMIN, 2013). O próprio Kant aprofunda nessa questão ao apontar a tendência pacificadora das democracias modernas.

Chamayou, em Teoria do Drone, argumenta que desde o século XIX a relação com a guerra é marcada pela avaliação de seus custos de decisão por aquele que a toma. Há, pelos próprios princípios fundamentais republicanos, uma tendência a limitar o recurso da guerra por um jogo de cálculos próprios. Contudo, a partir do mesmo argumento de pacificação utilizado por Kant, o que se observa é um desencadeamento contrário, levando ao que Chamayou denomina "militarismo democrático". Nesse modelo, a aversão pelas perdas passa a selecionar quais perdas se constituem como tal.

\author{
Nós não queremos ir à Guerra/ \\ Mas, por Deus, se for preciso fazê-la/ \\ Ficaremos aquecidos em casa/ \\ Deixando-a ser feita por nossos bravos indianos \\ Canção britânica, 1878 (CHAMAYOU, 2015: 132)
}

A canção demonstra essa passagem de um cálculo racional que mede os custos, entendendo a possibilidade de delegação de perdas. Retira daquele que toma a decisão a responsabilidade direta. Tendo em vista que, em uma democracia, a autoridade se faz por consentimento, há uma suposta coletivização da decisão, ao passo que certa nulidade de responsabilização é conferida por delegação dos custos (evidente no caso da metrópole britânica).

No processo de atualização dessas dinâmicas, é possível identificar que o fundamento bélico, originador da forma Estado e também sua garantia de existência, recria antagonismos e cálculos quanto ao custo/benefício das ações. Assim, o inimigo é aproximado, de tal forma que sua intimidade cria temores de identificação: o inimigo pode ser qualquer um, inclusive você. Com efeito, relações de consentimento são realinhadas não mais pela troca por proteção, conforme vimos anteriormente, mas porque não consentir pode significar atacar a garantia do Estado - ou melhor, te colocar nesse lugar - já que estamos em um modelo de Estado em que todos estão sob suspeita, ainda que com

16 Algo similar ocorreu no Brasil, dentre outros tantos exemplos, em sua participação na Guerra do Paraguai (1865-1870). O período permite afirmar que o embranquecimento da nação foi um dos principais catalisadores do projeto. Com o incentivo para o envio de soldados negros em troca de sua liberdade, a população foi reduzida - números absolutos - em um milhão de pessoas negras (FLAUZINA, 2005). 
abismais discrepâncias.

As alterações nas políticas de controle do Estado, entretanto, demarcam uma mudança de paradigma. Segundo Chamayou, é constatável a proeminência do paradigma do antiterrorismo sobre o da contrainsurgência: "enquanto a contrainsurgência é essencialmente político-militar, o antiterrorismo é fundamentalmente policial-securitário." A diferença, antes de mais nada, é no modo de conceber o inimigo.

Se o primeiro paradigma considera os insurgentes como os 'representantes de reivindicações mais profundas no seio de uma sociedade', e que, para combatê-lo de forma eficaz é preciso empenharse em entender sua razão de ser, o segundo, etiquetando-os como 'terroristas', concebe-os antes de tudo como 'indivíduos aberrantes', personalidades perigosas, se não como simplesmente loucos, ou pura encarnação do mal” (CHAMAYOU, 2015: 81).

Os objetivos, assim, passam a ser de neutralização do inimigo. Um inimigo que perde características estratégicas, ideológicas e até mesmo sua pertença à população: "não se negocia com terroristas". Chamayou observa que "enquanto a estratégia de contrainsurgência implica, além da força bruta, compromisso, ação diplomática, pressões e acordos coercitivos, o antiterrorismo exclui todo tratamento político do conflito". (CHAMAYOU, 2015: 81).

Note que estamos abordando a temática quanto à alteração de paradigmas do Estado, não fica evidente, entretanto, se o alvo das ações de controle do Estado se modificam profundamente. Os discursos e ações (políticas e jurídicas) internacionalmente mobilizados como "guerra ao terror" atribuem traços e condutas ao modelo contemporâneo de Estado. O "terrorista", contudo, é produto da estratégia individualizante de criminalização e perseguição a pautas insurgentes ou reivindicativas da população. No caso brasileiro, a perseguição ao MST por leis de organização criminosa e antiterrorismo é expressão trágica disso.

A centralidade do medo enquanto afeto político produz um corpo social tendencialmente paranoico, atado à lógica imunizante contra toda violência que coloca em risco a vida social. A subjetividade coletiva, pautada pela chave securitária, organiza modos de evitar a imprevisibilidade e a insegurança. Com efeito, esse é também o corpo social que demanda controle e autoridade estatais, autorizando inclusive que sejam manifestas com violência, desde que resguardado seu monopólio. Fica assegurado, assim, o fundamento de que é necessária a perpetuação funcional das potencialidades de perigo, violência e insegurança absoluta. Dinâmica essa estabelecida como gestão e gestação do medo nas democracias contemporâneas, característica fundamental da política do medo (SARTORIO, 2018).

A lei antiterrorismo ilustra, de modo concreto, as atividades estatais de 
controle que passam por suspensão arbitrária de direitos. O terrorismo, o medo e a política formam, segundo Castells (2018):

o frontispício da vida cotidiana, em que os cidadãos aceitam que os vigiem e os controlem eletronicamente, os revistem em suas viagens, que os detenham preventivamente, que militarizem o espaço público. Porque essas precauções são sempre em relação "aos outros", àqueles cuja etnia ou religião os torna suspeitos de ser suspeitos (CASTELLS, 2018:29).

Ao partirmos da dinâmica de delegar ao "outro" o lugar da suspeita, nos voluntariamos à vigilância e a traços de autoritarismo de Estado. O controle assume a aparência de ser sobre o "outro", ainda que tantas das limitações atinjam, controlem e coíbam igualmente aqueles que se veem como objeto da segurança e não do medo.

Os processos de estigmatização nas relações de alteridade social, que define o outro como esse potencial violador da vida, lançam à esteira das configurações de "inimigo" uma série de representações do medo socialmente assimiladas. Michel Misse (2010) sugere, com sua abordagem sobre a "sujeição criminal", que as categorias "bandido", "vagabundo", "criminoso" tratam de sujeitos produzidos pela interpelação da polícia, da moralidade pública e das leis penais - a esse espectro podemos facilmente adicionar a figura do terrorista.

Encarnar a multitude de medos é, nesses termos, instrumentalizar as disjunções sociais. $\mathrm{O}$ autoritarismo lança mão de uma operação cognitiva em que os seres marcados por estigmas sociais - portadores do medo - são mobilizados como "a ameaça" legitimadora de práticas autoritárias. Como sustenta Misse, os sujeitos aos quais atribuímos rótulos por estigmas sociais não são sujeitos incriminados quaisquer. Um sujeito nesse espectro de denominações é "agente de práticas criminais para as quais são atribuídos os sentimentos morais mais repulsivos, o sujeito ao qual se reserva a reação moral mais forte" (MISSE, 2010: 17).

Assim, o Estado contemporâneo que tem a coerção como aspecto central está necessariamente preocupado com o convencimento da população. A persuasão se dá não apenas por propaganda ideológica no nível discursivo, mas também pela própria materialidade da vida, que experimenta um cotidiano de violência rotinizada com estética de "caos". Essa realidade é repetidamente associada ao "descaso", "ausência de controle" e "desordem". O remédio, por lógica, requer ordem, ostensividade e controle. Isso se reflete na forma do Estado contemporâneo, caracterizado pelo repertório de ações voltadas à contenção de setores populares. Sujeitos localizados em "zonas hostis ${ }^{17 "}$ da cidade, atravessados por marcadores sociais estigmatizantes (raça, classe, etnia, gênero) que os situam como "inimigos" a serem combatidos. 
A face do acusado de terrorismo não será a de qualquer sujeito. E provavelmente será a antítese do homem rico, branco, do norte global. Isso porque, segundo Misse, a alteridade se dá por "acúmulo social da violência". Fatores sociais se alimentam reciprocamente em dinâmica circular acumulativa, gerando, de um lado, acúmulo de desvantagens para um segmento da população e, de outro, estratégias aquisitivas de vantagem. As atribuições que resultam disso são, ironicamente, partilhadas tanto pelos próprios "agentes criminais quanto por agentes encarregados de reprimi-los" (MISSE, 2010:18).

A perseguição a determinados setores sociais não é novidade. Menos ainda a estratégia do Estado de contenção das reivindicações sociais, conforme marca o paradigma predominante até o atentado de 11/9, a contrainsurgência. Ao apreendermos a realidade por sua dinâmica processual, temos aqui uma alteração estratégica do Estado nas práticas para constituição de consentimentos, mecanismos de controle e garantia da dominação política. Por outro lado, os alvos políticos, recriados e atualizados em discurso, se mantém como os mesmos corpos socialmente vulneráveis.

Não buscamos encerrar, mas estimular discussões que nos parecem centrais para seguir pensando as transformações dos Estados na atualidade, de modo a lidar com impasses teóricos sem desvincular o fenômeno de sua historicidade, geopolítica e relacionalidade. Ao contrário, é necessário enfatizar essas dimensões de modo a compreender continuidades, além de rupturas e projeções. Os contornos assumidos pelo Estado contemporâneo que estabelecem inimigos não apenas externos, mas internos, recriam dinâmicas nacionais. A proximidade com o inimigo afeta subjetivamente as interações sociais porque assim toda relação se configura enquanto risco, potencial ameaça. Recursos de vigilância, dronização, controle por militarização passam a ser não somente legitimados, mas requeridos. Ao mesmo tempo, os antagonismos são crescentemente tratados com vistas à eliminação do outro, o que conforma um tratamento da política pela veia bélica.

\section{REFERÊNCIAS}

AGAMBEN, Giorgio. Estado de Exceção. São Paulo: Boitempo, 2004.

ARTIGO 19 ONG. Relatório. Disponível em: $<$ http://protestos.artigo19.org/Protestos_no_Brasil_2013.pdf> Acessado em: 15 de nov. de 2019.

CHAMAYOU, Grégoire. Teoria do Drone. Trad. Célia Euvaldo. Ed. CosacNaify, 2015.

CHARLEUX, João Paulo. Quem é a ministra que renunciou em protesto contra 
a lei antiterror da França. 2016. Disponível em: <https://www.nexojornal.com.br/expresso/2016/01/27/Quem-\%C3\%A9-aministra-que-renunciou-em-protesto-contra-a-lei-antiterror-da-Fran \%C3\%A7a> Acessado em: 26 de jun. de 2020.

CHOMSKY, Noam A. O Império Americano: hegemonia ou sobrevivência. Rio de Janeiro: Elsevier, 2004.

CHOMSKY, N.; ACHCAR, G. Perilous Power: The Middle East \& U.S. Foreign Policy. Ed: Penguin Books, 2008.

CONCEIÇÃO, Thayla Fernandes; ZANOTTELI, Breno. Discursos oficiais sobre terrorismo e terrorismo de Estado no Brasil: criminalizações e movimentos sociais. Porto Alegre: A sociologia do direito entre discurso e ação, 2016.

FANTTI, Bruna. Ministro da Defesa diz que cerca de 500 mil pessoas são suspeitas de terrorismo. 2016. Disponível em: <http://odia.ig.com.br/rio-dejaneiro/2016-07-16/ministro-da-defesa-diz-que-cerca-de-500-mil-pessoas-saosuspeitas-de-terrorismo.html> Acessado em: 20 de dez. de 2018.

FLAUZINA, Ana Luiza Pinheiro. Corpo negro caído no chão: O sistema penal e o projeto genocida do Estado brasileiro. Editora Brado, 2017.

JASMIM, Marcelo. Despotismo e História na Obra de Alexis de Tocqueville. São Paulo: IEA USP, 2013. Disponível em: <http://www.iea.usp.br/publicacoes/textos/jasmintocqueville.pdf> Acessado em: 20 de nov. de 2019.

MISSE, Michel. Crime, Sujeito e Sujeição Criminal. São Paulo: Lua Nova (79, 15-38), 2010.

NETSAL. Dossiê Temático n.3. As Jornadas de Junho em perspectiva global. 2013. Disponível em: <https://www.academia.edu/10068329/_2013_As_Jornadas_de_Junho_em_per spectiva_global> Acessado em: 02 de dez. de 2019.

O’DONNELL, Guillermo. El estado burocrático-autoritário: triunfos, derrotas y crisis. Buenos Aires: Editorial Belgrano, 1996.

PASTANA, Débora Regina. Terrorismo, medo e recrudescimento do controle: traços da política punitiva no mundo contemporâneo, in Dossiê Ecos do 11/09: Dez anos depois, 2011.

SAFATLE, Vladimir. O circuito dos afetos. São Paulo: CosacNaify, 2016.

SARTORIO, Lara. Afetos, corpos e territórios: medo e violência na Maré e na Palestina. Rio de Janeiro: Dissertação de mestrado do Iesp/UERJ, 2018. 
TILLY, Charles. Coerção, Capital e os Estados Europeus. São Paulo: EdUSP, 1996. War making and state making as organized crime. 1985. In: P.Evans, D. Rueschemeyer e T. Skocpol (Orgs.) Bringing the state back in. Cambridge: Cambridge University Press, p.169-191.

.Terror, Terrorism, Terrorists. New York: Sociological Theory, 2004.

WARDLAW, Grant. Political Terrorism: Theory, Tactics And CounterMeasures. Cambridge: Cambridge University Press, 1982. 218pp. 


\title{
ANTITERRORISM LAW IN BRAZIL AND THE CENTRALITY OF FEAR IN THE TRANSFORMATIONS OF CONTEMPORARY STATES
}

\begin{abstract}
Since September 11 attack in New York, in 2001, terrorism has become a central theme in society. Since then, extreme measures to control territories and populations are justified, with global (geo) political and legal implications. In the period following the attack, measures and legislation, such as the well-known Patriot Act, were determined by the US government, in order to typify terrorism and expand the power and prerogative of governments in its combat, authorizing extralegal resources, surveillance and social control. What initially appeared to be a reactive and punctual political strategy has become a State project followed by paradigm shift that aspires to international expansion through a commitment to the "war on terror". In Brazil, with the significant demonstrations of June 2013, legal and political developments in the sense of "combating terrorism" were articulated by governments. Intriguing posture, given the absence of terrorist attacks in the country's history. In this article, we reflect on the Brazilian case, using qualitative method and bibliographic review, observing a global pattern of politics of fear and shifts from the figure of the external enemy to the internal as mechanisms for authorizing authoritarian policies.
\end{abstract}

Key Words: Terrorism. Antiterrorism Law. State. Fear. Social Movements.

\section{LEY ANTITERRORISMO EN BRASIL Y LA CENTRALIDAD DEL MIEDO EN LAS TRANSFORMACIONES DE LOS ESTADOS CONTEMPORÁNEOS}

Resumén: Desde el ataque del 11 de septiembre de 2001 en Nueva York, el terrorismo se ha convertido en un tema central en la sociedad. Desde entonces, las medidas extremas para controlar territorios y poblaciones están justificadas, con implicaciones globales (geo) políticas y legales. En el período posterior al ataque, el gobierno de los Estados Unidos determinó medidas y legislación, como la conocida Ley Patriota, para tipificar el terrorismo y ampliar el poder y la prerrogativa de los gobiernos en su combate, autorizando recursos extralegales, vigilancia y control social. Lo que inicialmente parecía ser una estrategia política reactiva y puntual se ha convertido en un proyecto estatal con un cambio de paradigma que aspira a la expansión internacional a través de un compromiso con la "guerra contra el terror". En Brasil, con las significativas manifestaciones de junio de 2013, los gobiernos articularon los desarrollos legales y políticos en el sentido de "combatir el terrorismo". Postura intrigante, dada la ausencia de ataques terroristas en la historia del país. En este artículo, reflexionamos sobre el caso brasileño, utilizando método cualitativo y revisión bibliográfica, observando un patrón global de políticas de miedo y cambios de la figura del enemigo externo a lo interno como mecanismos para autorizar políticas autoritarias.

Palabras clave: Terrorismo. Ley Antiterrorista. Estado. Miedo. Movimientos sociales. 